\title{
Efeitos de diferentes sistemas de cultivo in vitro sobre o crescimento de folículos pré-antrais isolados de ovários de fetos bovinos
}

Andréa Cristina BASSO${ }^{1}$ Joaquim Mansano GARCIA ${ }^{2}$ Cesar Roberto ESPER ${ }^{2}$

\section{Correspondência para:}

Rua Abdo Muanis 1101, apto 74. Cep: 15090-140. Bairro Nova Redentora. São José do Rio Preto-SP; e-mail:acbusp@hotmail.com

Recebido para publicação: 22/11/2005 Aprovado para publicação: 26/03/2007

\begin{abstract}
1 - Departamento de Reprodução Animal da Faculdade de Medicina Veterinária e Zootecnia da Universidade de São Paulo, São Paulo-SP

2 - Departamento de Medicina Veterinária Preventiva e Reprodução Animal da Faculdade de Ciências Agrárias e Veterinárias da Universidade Estadual Paulista, Jaboticabal-SP
\end{abstract}

\section{Resumo}

O objetivo deste estudo foi aplicar diferentes sistemas de cultivo in vitro para folículos pré-antrais de fetos bovinos da raça Nelore no último trimestre de gestação e para identificar o sistema mais eficiente durante o crescimento dos folículos isolados. Para isso, folículos préantrais foram isolados mecanicamente e submetidos ao cultivo individual, por 9 dias, em meio não suplementado ou suplementado com soro fetal bovino (SFB), albumina sérica bovina (BSA) ou suplemento definido sintético substituto do soro KnockoutSR (KNO). Avaliou-se ainda, o efeito do gel de colágeno ou monocamada de fibroblastos fetais bovinos como substrato para o cultivo in vitro. A avaliação do aumento de diâmetro folicular foi realizada no dia da colheita ( 0 hora) e a cada 72 horas de cultivo. A associação entre meio suplementado com SFB e uso de gel de colágeno como substrato foram significativamente mais efetivos sobre o aumento do diâmetro folicular quando comparados aos demais tratamentos. Quando fragmentos de tecido ovariano foram submetidos ao cultivo in vitro, não houve preservação da ultraestrutura folicular por mais de 3 dias de cultivo, em qualquer dos tratamentos utilizados. Ainda não está estabelecido um sistema de cultivo adequado que sustente a diferenciação e multiplicação das células da granulosa e que mantenha o contato das mesmas com o oócito para prover moléculas e fatores que supram a demanda metabólica. Entendemos que esta pesquisa apresentou avanços promissores na busca pelo estabelecimento um sistema de cultivo in vitro de folículos pré-antrais em bovinos.

\section{Introdução}

Muitos estudos sobre a fisiologia ovariana concentram-se nos estádios terminais do desenvolvimento folicular e demonstram os vários mecanismos endócrinos, parácrinos e autócrinos que regulam o crescimento folicular. ${ }^{1,2,3,4}$ Por outro lado, as pesquisas sobre os fatores que controlam o início do desenvolvimento do folículo primordial ao longo da fase préantral ainda são limitadas, principalmente no que se refere às espécies monovulares, como bovinos e humanos, os quais necessitam de vários meses para que os folículos primordiais cheguem ao estádio antral. Mais recentemente, os estudos têm se voltado para o entendimento dos fatores que controlam a foliculogênese inicial com auxílio de protocolos para cultivo in vitro de folículos pré-antrais de diferentes espécies, como roedores $^{5}$, suínos ${ }^{6}$, bovinos ${ }^{7}$, humanos ${ }^{8}$ e pequenos ruminantes ${ }^{9}$. Nestas espécies, os esforços resultaram em nascimentos de prole a partir de folículos desenvolvidos e maturados in vitro. Entretanto, desenvolver in vitro folículos pré-antrais, requer monitoramento constante dos fatores 
envolvidos no seu crescimento durante todo o período de cultivo. ${ }^{10}$

Durante a transição folicular do estádio primordial para o secundário, já foi demonstrado em estudos anteriores ${ }^{11} \mathrm{a}$ ocorrência de uma série de modificações citoplasmáticas no oócito, as quais representam processos precursores da maturação. Nesse sentido, a aquisição e estocagem de várias formas de RNA e proteínas são indispensáveis para o futuro desenvolvimento folicular. ${ }^{12} \mathrm{O}$ Soro Fetal Bovino (SFB) e a Albumina Sérica Bovina (BSA) são comumente adicionados aos meios de cultivo como suplemento de proteínas com o objetivo de melhorar a eficiência do sistema, embora variações destas fontes protéicas produzam efeitos divergentes durante o cultivo. ${ }^{13}$

$O$ desenvolvimento in vitro de folículos pré-antrais de camundongos ${ }^{14}$, bovinos ${ }^{7}$ e suínos ${ }^{15}$ foram conduzidos com gel de colágeno e mostraram eficiência na manutenção da estrutura tridimensional dos folículos. Folículos primordiais e primários, isolados de ovários humanos e cultivados em gel de colágeno apresentaram crescimento apenas nas primeiras 24 horas ${ }^{16}$ denotando a escassez de recursos para a manutenção da viabilidade folicular. Tentativas têm sido feitas para determinar em qual estádio do desenvolvimento os folículos pré-antrais tornam-se dependentes de FSH, bem como qual seria a dose a ser utilizada in vitro para obtenção de resultados efetivos. Adriaens, Cortvrindt e Smitz ${ }^{17}$ obtiveram embriões viáveis a partir de oócitos de folículos pré-antrais de camundongo cultivados in vitro, com 10 $\mathrm{mUI} / \mathrm{ml}$ de FSH recombinante em todo o período de cultivo, desde a fase pré-antral.

Considerando o domínio destas biotecnologias, haveria a possibilidade de se explorar os estoques de oócitos inclusos em folículos pré-antrais a fim de se fornecer material para técnicas de reprodução assistida mais complexas e tratamento de infertilidade clínica ${ }^{18}$, bem como no melhoramento genético de animais de produção ${ }^{19}$. Diante das dificuldades em se estabelecer protocolos eficientes para a produção de oócitos viáveis a partir de folículos préantrais de animais como os bovinos, a maioria dos estudos é de caráter investigativo e ainda não têm aplicação prática. ${ }^{20}$

O objetivo deste trabalho foi verificar o efeito de três diferentes suplementações protéicas em combinação com um substrato à base de colágeno ou uma monocamada de fibroblastos, sobre a taxa de crescimento in vitro de folículos pré-antrais de fetos bovinos, durante 216 horas de cultivo.

\section{Material e Método}

\section{Folicular \\ Colheita dos Ovários e Isolamento}

Ovários de fetos bovinos no último trimestre de gestação (idade gestacional avaliada segundo os critérios de Nichols ${ }^{21}$ foram colhidos assepticamente em abatedouro, armazenados em meio TCM199 (M5017 - Sigma Chemical Co), sulfato de amicacina, $20 \mathrm{mM}$ de tampão Hepes (H3784, H6147, Sigma Chemical Co), 5 mM de Bicarbonato de Sódio (1.06329.1000, Merk), 0,23 mM de Piruvato de Sódio (44094 - Biochemical) e $0,5 \%$ de $\mathrm{BSA}$, a $35^{\circ} \mathrm{C}$, para transporte até o laboratório.

Cada par de ovários foi processado para o isolamento folicular descrito em estudos prévios ${ }^{11}$, utilizando um cortador de tecidos "Tissue Chopper" (The Mickle Laboratory Engineering CO, Gomshal, Surrey, England). Os folículos isolados foram selecionados com o auxílio de um microscópio invertido (Fluorovert, Leitz, Germany), transferidos para gotas de meio de lavagem, classificados e destinados aos tratamentos para cultivo in vitro.

\section{Isolados}

\section{Cultivo in vitro dos Folículos}

O meio de cultivo base utilizado em todos os tratamentos realizados foi o M199 (M5017 - Sigma Chemical Co), acrescido de $80 \mu \mathrm{g} / \mathrm{mL}$ de Amicacina, $25 \mathrm{mM}$ de Bicarbonato de Sódio, $16 \mathrm{mg} / \mathrm{mL}$ de ITS (I1884, Sigma Chemical Co), 0,1 mg/mL de L-ácido ascórbico (A 4544, Sigma 
Chemical Co), 0,23 mM Piruvato de Sódio, $2 \mathrm{mM}$ de Hipoxantina (M9377, Sigma Chemical Co) e $1 \mathrm{UI} / \mathrm{mL}$ de $\mathrm{FSH}$ recombinante humano (Puregon/300UI, Serono). De acordo com o tratamento utilizado, acrescentou-se ao meio: $0,3 \%$ de BSA, 7,5\% de SFB (Cultlab, Campinas-SPBrasil) ou 7,5\% de substituto sintético KNO (Knockout ${ }^{\mathrm{TM}}$ SR - 10828028 - Gibco BLR). Ao grupo controle $(\mathrm{CON})$, nenhuma fonte protéica foi acrescida. Em combinação aos suplementos protéicos utilizados, foram preparados previamente dois substratos diferentes, os quais, serviam de auxiliares na manutenção da estrutura tridimensional dos folículos ao longo do cultivo. No primeiro substrato, utilizou-se uma camada de colágeno (COL) de cauda de rato. O segundo substrato, constituído por uma monocamada de fibroblastos (FB) extraídos de fetos bovinos, de maneira semelhante ao primeiro foi adicionado em placas de 96 fossas (Limbro, 76-032-05, Flow Lab, Inc. Virginia, USA). As fossas recobertas com o respectivo substrato foram preenchidas com $80 \mathrm{~mL}$ do meio de cultivo de acordo com o tratamento e de $60 \mathrm{~mL}$ de óleo mineral, a fim de minimizar possível contaminação e a evaporação do meio. Finalmente, as placas foram incubadas em uma atmosfera umidificada, com $5 \%$ de $\mathrm{CO}_{2} \mathrm{em}$ ar e temperatura de $38,5^{\circ} \mathrm{C}$, por 15 minutos, antes de receberem os folículos isolados.

Os folículos isolados considerados viáveis (exibindo oócito central rodeado por camadas de células granulosas intactas e membrana basal preservada) foram selecionados em três diferentes classes de tamanhos, sendo elas: menores que $60 \mathrm{~mm}$ de diâmetro (TAM 1), entre 60 e $80 \mathrm{~mm}$ (TAM 2) e maiores que $80 \mathrm{~mm}$ de diâmetro (TAM 3). As médias de tamanho folicular iniciais foram semelhantes entre os 8 tratamentos e mensurados com auxílio de ocular micrométrica (Olympus WH10X-H/ 22, Japan) acoplada ao microscópio invertido com contraste de fase (Olympus IX70 - Japan). Os folículos foram transferidos individualmente para as placas de 96 fossas procedendo-se o cultivo in vitro de acordo com os diferentes tratamentos: T1 (SFB+COL), T2 (BSA+COL), T3 $(\mathrm{KNO}+\mathrm{COL}), \mathrm{T} 4(\mathrm{CON}+\mathrm{COL}), \mathrm{T} 5$ $(\mathrm{SFB}+\mathrm{FB}), \mathrm{T} 6(\mathrm{BSA}+\mathrm{FB}), \mathrm{T} 7(\mathrm{KNO}+\mathrm{FB})$, T8 (CON+ FB). No dia inicial de cultivo, realizou-se a primeira avaliação do diâmetro folicular, para determinar o diâmetro folicular inicial (AV1) em micrômetros. Dois terços do volume de meio foram substituídos por igual volume de meio fresco, a cada 72 horas. As avaliações posteriores foram realizadas às 72 (AV2), 144 (AV3) e às 216 horas (AV4) de cultivo. O período total de cultivo foi de 9 dias.

\section{Análise Estatística}

Para avaliar a variação do crescimento folicular ao final do período de cultivo, as medidas do diâmetro folicular, no momento da colheita (AV1) e ao final do cultivo (AV2). $\mathrm{O}$ experimento constou de 10 repetições $(\mathrm{n}=1726)$. A eficiência dos parâmetros testados foi considerada pela variação do diâmetro folicular ao final das $216 \mathrm{~h}$ de cultivo (AV4-AV1), para isso foi realizada uma análise de variância entre os tratamentos e as médias foram confirmadas pelo Teste de Duncan (SAS System) ao nível de significância de P $<0,05$.

Para avaliar a manutenção do desenvolvimento folicular ao longo do período de cultivo, as medidas do diâmetro folicular em 3 diferentes intervalos tempo de cultivo foram consideradas (DF1, DF2 e DF3), sendo que DF1 = AV2 - AV1, DF2 $=\mathrm{AV} 3-\mathrm{AV} 2$ e DF3 = AV4 - AV3. Também foram considerados os tamanhos médios dos folículos no dia inicial de cultivo (TAM1, TAM2, TAM3). Os diferentes tratamentos foram comparados considerando os efeitos dos diferentes fatores estudados: fonte protéica (FP), substrato (SB), tamanho inicial (TAM) e suas interações, sobre as diferenças de diâmetro folicular (DF1, DF2 e DF3), como variáveis dependentes. As variáveis e suas combinações foram submetidas à Análise de Variância por Comparações Múltiplas (LSMeans - SAS System) e as médias foram ajustadas para os seus Quadrados Mínimos 
e confirmadas pelo Teste de Tukey-Kramer $(\mathrm{P}<0,05)$.

\section{Resultado}

Análise da Percentagem de Crescimento Folicular ao Final do Período de Cultivo In Vitro

O diâmetro médio dos folículos submetidos ao cultivo in vitro foi de 74,65 \pm 2,47 $\mathrm{mm}$. A análise das curvas de crescimento mostrou diferenças no aumento de diâmetro dos folículos entre os tratamentos (Figura 1). Ao considerarmos as médias gerais do aumento do diâmetro folicular ao final das 216h, mostrados na tabela 1, observamos as diferenças entre os oito tratamentos utilizados quanto às percentagens de crescimento folicular ao final do cultivo. Folículos de diferentes tamanhos iniciais, em todos os tratamentos, tiveram alterações no seu diâmetro ao longo de $216 \mathrm{~h}$ de cultivo in vitro. No entanto, nenhum dos tratamentos proporcionou crescimento folicular que evidenciasse o início da formação de antrum. Os tamanhos foliculares iniciais foram significativamente semelhantes para os 8 tratamentos realizados. Os resultados mostrados na tabela 1 e na figura 2 demonstram que SFB+COL $(\mathrm{T} 1=20,71 \%)$ proporcionou um aumento significativo $(\mathrm{p}<0,05)$ sobre o diâmetro

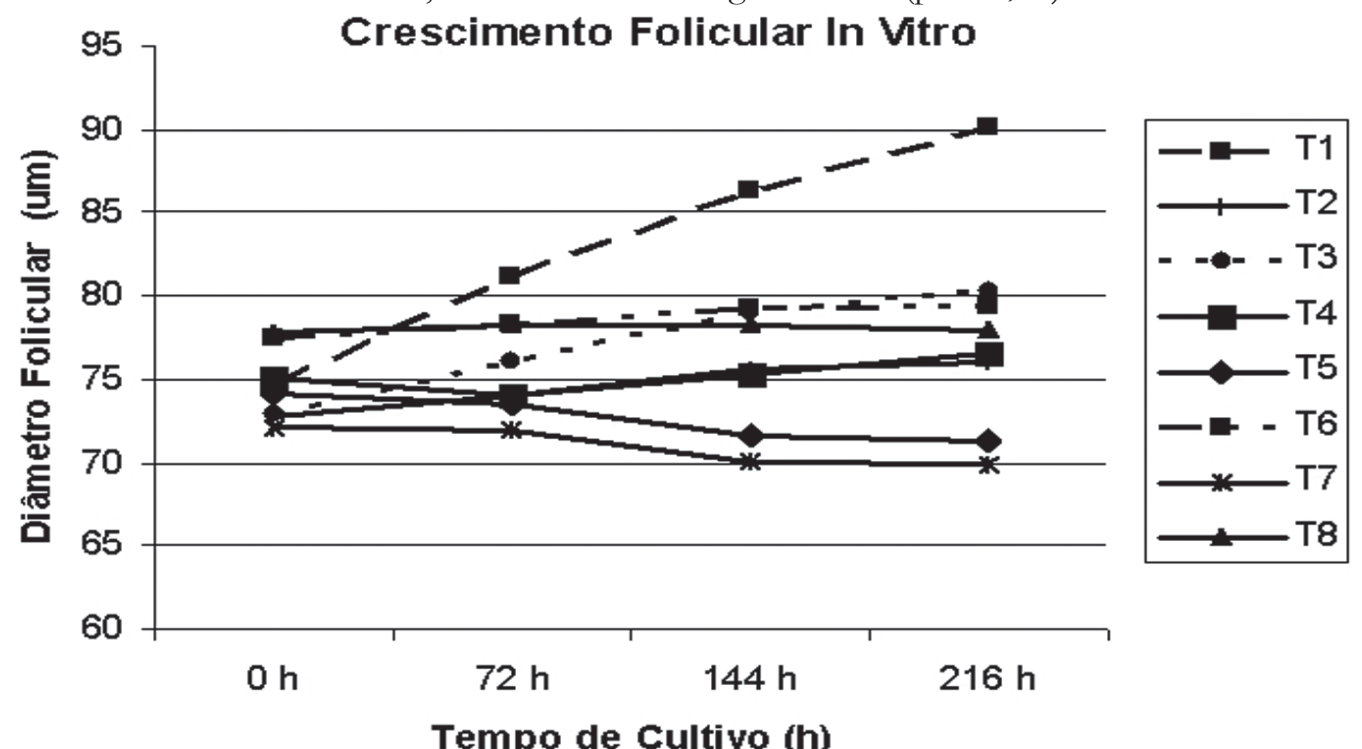

Figura 1 - Padrão de crescimento de folículos pré-antrais de fetos bovinos cultivados in vitro, isoladamente, em meio M199 com SFB e colágeno (T1); com BSA e colágeno (T2); com Knockout e colágeno (T3), sem suplementação protéica e com colágeno (T4); com SFB e monocamada de fibroblastos (T5); com BSA e monocamada de fibroblastos (T6); com Knockout e monocamada de fibroblastos (T7) ou sem suplementação protéica e com monocamada de fibroblastos (T8), ao longo de $216 \mathrm{~h}$ de cultivo in vitro

Tabela 1 - Valores médios de aumento de diâmetro $(\mathrm{mm})$ de folículos pré-antrais de fetos bovinos submetidos a diferentes tratamentos. Jaboticabal, 2005

\begin{tabular}{cccccc}
\hline \multirow{2}{*}{ Grupos } & \multicolumn{5}{c}{ Avaliações do diâmetro folicular ao longo do cultivo in vitro $(\mu \mathrm{m})$} \\
\cline { 2 - 6 } & $\mathbf{0 h}$ & $\mathbf{7 2 h}$ & $\mathbf{1 4 4 h}$ & $\mathbf{2 1 6 h}$ & $\mathbf{\%} \mathbf{( 0 \mathbf { h }}$ a 216h) \\
\hline T1(SFB+COL) & 74,63 & 81,11 & 86,37 & 90,09 & $20,71^{\mathrm{a}}$ \\
T2(BSA+COL) & 72,81 & 73,98 & 75,63 & 76,01 & $4,40^{\mathrm{b}}$ \\
T3(KNO+COL) & 72,98 & 76,11 & 79,11 & 80,29 & $10,01^{\mathrm{b}}$ \\
T4(CON+COL) & 75,11 & 74,02 & 75,33 & 76,52 & $1,88^{\mathrm{b}}$ \\
T5(SFB+FB) & 74,13 & 73,59 & 71,74 & 71,30 & $-3,81^{\mathrm{b}}$ \\
T6(BSA+FB) & 77,50 & 78,30 & 79,26 & 79,46 & $2,53^{\mathrm{b}}$ \\
T7(KNO+FB) & 72,17 & 71,96 & 70,11 & 70,00 & $-3,01^{\mathrm{b}}$ \\
T8(CON+FB) & 77,83 & 78,26 & 78,26 & 78,04 & $0,27^{\mathrm{b}}$ \\
\hline
\end{tabular}

Letras diferentes na mesma coluna indicam diferenças significativas pelo Teste de Duncan $(\mathrm{P}<0,05)$. 


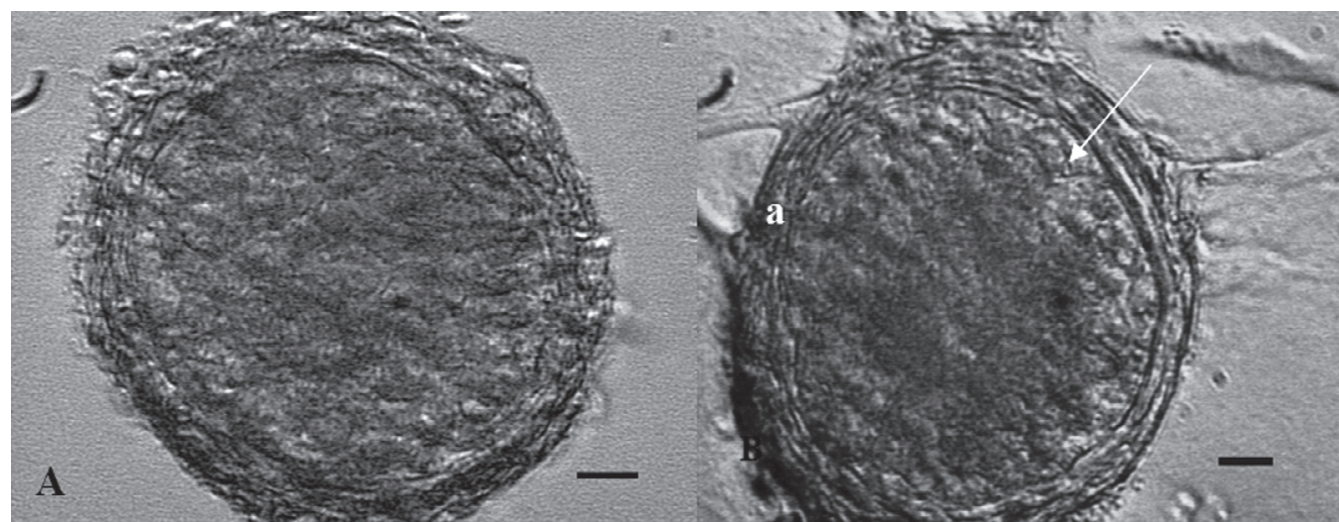

Figura 2 - (A) Micrografia sob Microscopia de Inversão de um folículo secundário após o isolamento. Nota-se mais de duas camadas de células granulosas cuboidais ao redor do oócito (seta) e membrana basal totalmente preservada (a). À Oh, este folículo apresentou $90 \mu \mathrm{m}$ de diâmetro. 40X. Barra $=13 \mu \mathrm{m}$. (B) Após 216h de cultivo no meio M199 com SFB e colágeno, o folículo estava com 120 m de diâmetro, apresentava proliferação das células granulosas e prolongamentos das células da membrana basal (seta). Houve preservação da estrutura tridimensional do folículo. 40X. Barra $=35 \mu \mathrm{m}$

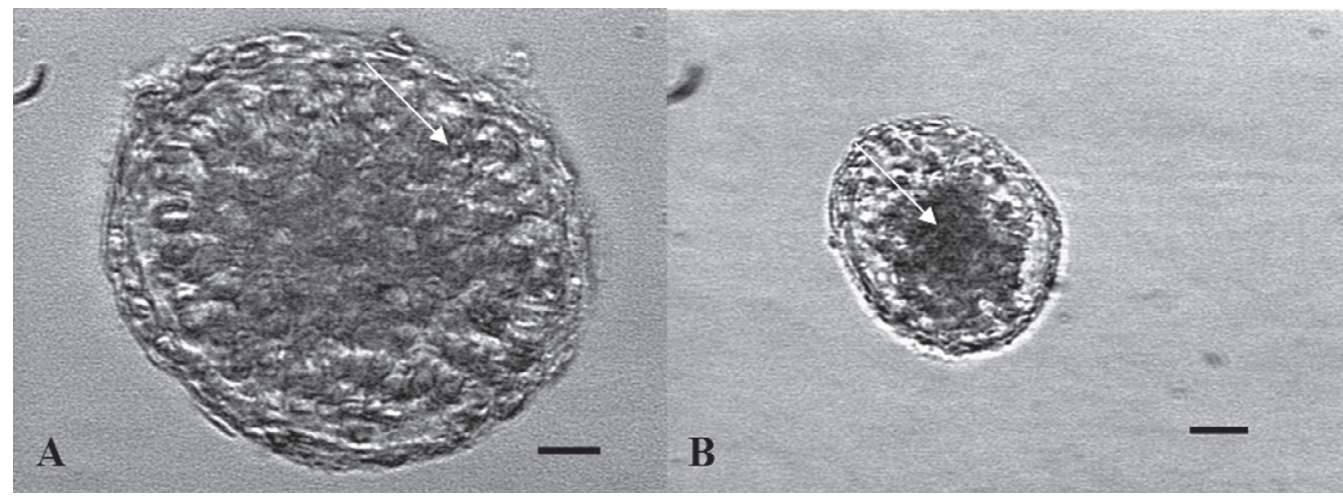

Figura 3 - (A) Micrografia sob Microscopia de Inversão de um folículo secundário após o isolamento. Nota-se mais de duas camadas de células granulosas cuboidais ao redor do oócito (seta). À Oh, este folículo tinha $105 \mathrm{~mm}$ de diâmetro. 40X. Barra $=13 \mu \mathrm{m}$. (B) Após 216h de cultivo em meio M199 com BSA e colágeno apresentou $100 \mu \mathrm{m}$ de diâmetro e visível retração e escurecimento do oócito (seta), com condensação das células granulosas e espaçamento entre elas. 20X. Barra $=30 \mu \mathrm{m}$

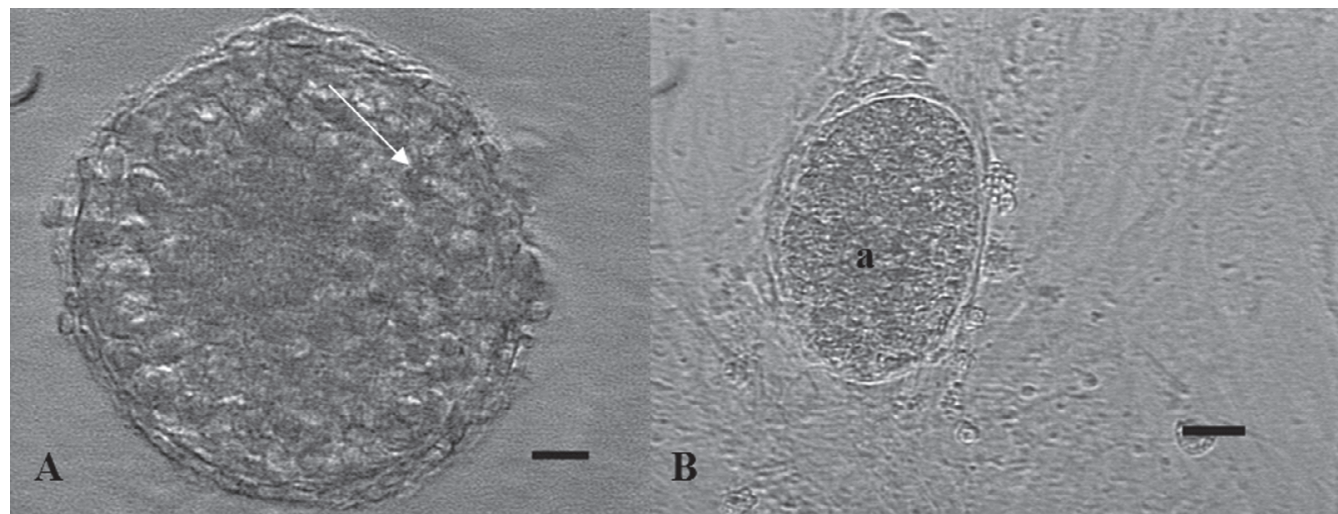

Figura 4 - (A) Micrografia sob Microscopia de Inversão de folículo secundário após o isolamento. Nota-se mais de duas camadas de células granulosas cuboidais ao redor do oócito (seta). À Oh, apresentava $90 \mathrm{~mm}$ de diâmetro. 40X. Barra $=13 \mu \mathrm{m}$. (B) Após 216h de cultivo em meio M199 com SFB monocamada de fibroblastos estava alongado, com $75 \mu \mathrm{m}$ de diâmetro médio, aspecto de degeneração, oócito retraído e células escurecidas (a). 20X. Barra $=25 \mu \mathrm{m}$ 
folicular em comparação aos outros tratamentos: $\mathrm{BSA}+\mathrm{COL}(\mathrm{T} 2=4,40 \%)$, $\mathrm{CON}+\mathrm{COL}(\mathrm{T} 4=1,88 \%), \mathrm{SFB}+\mathrm{FB}(\mathrm{T} 5=-$ $3,81 \%), \mathrm{BSA}+\mathrm{FB}(\mathrm{T} 6=2,53 \%), \mathrm{KNO}+\mathrm{FB}$ $(\mathrm{T} 7=-3,01 \%)$ e $\mathrm{CON}+\mathrm{FB}(\mathrm{T} 8=0,27 \%)$, porém não apresentou diferença significativa ao tratamento com $\mathrm{KNO}+\mathrm{COL}$ (T3 $=10,01 \%$ ). Todos os tratamentos cujo substrato foi o colágeno mantiveram a morfologia folicular até o final do cultivo (Figura 3). Por outro lado, observamos que os tratamentos com monocamada de fibroblastos não foram eficientes para a manutenção da viabilidade folicular, levando ainda à redução do diâmetro (Figura 4).

Análise do Crescimento Folicular ao Longo do Período de Cultivo, em Diferentes Intervalos de Tempo (DF1, DF2, DF3)

Ao considerarmos os efeitos de cada tratamento sobre o aumento do diâmetro folicular nos diferentes períodos de tempo (DF1, DF2, DF3) que, de acordo com a análise anterior, o T1 (SFB+COL) proporcionou maior aumento $(\mathrm{P}<0,05)$ de diâmetro folicular em relação às demais combinações estudadas em ambos os períodos de tempo analisados (Tabela 2). Podemos perceber ainda que, qualquer das fontes protéicas utilizadas em associação ao colágeno apresentou resultados superiores $(\mathrm{P}<0,05)$ em relação às mesmas quando utilizadas em associação à monocamada de fibroblastos. Observamos ainda que o KNO teve efeitos mais efetivos sobre o crescimento folicular (T3) em relação ao BSA (T2) e ao meio sem suplementação alguma (T4) $(\mathrm{P}<0,05)$.

O tamanho inicial dos folículos submetidos ao cultivo (Tabelas 3 e 4) não interferiu na proporção de aumento de diâmetro em nenhum dos intervalos de tempo avaliados (DF1, DF2 e DF3),

Tabela 2 - Efeito das combinações entre as diferentes fontes protéicas e os diferentes substratos sobre o aumento de diâmetro $(\mu)$ de folículos pré-antrais de fetos bovinos cultivados in vitro, em diferentes intervalos de tempo (DF1 $=0 \mathrm{~h}$ a $72 \mathrm{~h}, \mathrm{DF} 2=72 \mathrm{~h}$ a $144 \mathrm{~h}, \mathrm{DF} 3=144 \mathrm{~h}$ a $216 \mathrm{~h}$ ). Jaboticabal, 2005

\begin{tabular}{ccccccccc}
\hline Tempo (h) & \multicolumn{7}{c}{ Combinações entre Fontes Protéicas e Substratos } \\
\cline { 2 - 8 } & \multicolumn{2}{c}{ SFB } & \multicolumn{2}{c}{ BSA } & \multicolumn{3}{c}{ KNO } & CON \\
\cline { 2 - 8 } & T1/COL & T5/FB & T2/COL & T6/FB & T3/COL & T7/FB & T4/COL & T8/FB \\
\hline DF1 & $6,67^{\mathrm{b}}$ & $-0,53^{\mathrm{a}}$ & $1,21^{\mathrm{a}}$ & $3,94^{\mathrm{a}}$ & $3,19^{\mathrm{a}}$ & $-0,14^{\mathrm{a}}$ & $0,62^{\mathrm{a}}$ & $0,60^{\mathrm{a}}$ \\
DF2 & $5,31^{\mathrm{b}}$ & $-1,92^{\mathrm{a}}$ & $1,65^{\mathrm{a}}$ & $1,79^{\mathrm{a}}$ & $3,01^{\mathrm{a}}$ & $-1,81^{\mathrm{a}}$ & $0,90^{\mathrm{a}}$ & $0,00^{\mathrm{a}}$ \\
DF3 & $3,69^{\mathrm{b}}$ & $-0,47^{\mathrm{a}}$ & $0,39^{\mathrm{a}}$ & $0,08^{\mathrm{a}}$ & $1,16^{\mathrm{a}}$ & $-0,09^{\mathrm{a}}$ & $0,76^{\mathrm{a}}$ & $-0,16^{\mathrm{a}}$ \\
\hline
\end{tabular}

Tabela 3 - Efeito das combinações entre as diferentes fontes protéicas e os diferentes tamanhos iniciais (TAM1 = < $60 \mu \mathrm{m}$, TAM2 $=60$ a $80 \mu \mathrm{m}$, TAM3 $=>80 \mu \mathrm{m}$ ) de folículos pré-antrais de fetos bovinos sobre o aumento de diâmetro $(\mu \mathrm{m})$ em diferentes intervalos de tempo (DF1 $=0 \mathrm{~h}$ a $72 \mathrm{~h}$, DF2 $=72 \mathrm{~h}$ a $144 \mathrm{~h}$, DF3 $=144 \mathrm{~h}$ a $216 \mathrm{~h}$ ). Jaboticabal, 2005

\begin{tabular}{|c|c|c|c|c|c|c|c|c|c|c|c|c|}
\hline \multirow{3}{*}{ DF } & \multicolumn{12}{|c|}{ Interações entre Fontes Protéicas e Tamanhos Iniciais 1, 2 e 3} \\
\hline & \multicolumn{3}{|c|}{ SFB } & \multicolumn{3}{|c|}{ BSA } & \multicolumn{3}{|c|}{ KNO } & \multicolumn{3}{|c|}{$\mathrm{CON}$} \\
\hline & TAM1 & TAM2 & TAM3 & TAM1 & TAM2 & TAM3 & TAM1 & TAM2 & TAM3 & TAM1 & TAM2 & TAM3 \\
\hline DF1 & $2,83^{\mathrm{a}}$ & $3,28^{\mathrm{a}}$ & $3,08^{\mathrm{a}}$ & $4,38^{2}$ & $1,09^{\mathbf{a}}$ & $2,26^{\mathrm{a}}$ & $1,96^{\mathrm{a}}$ & $1,72^{2}$ & $0,88^{2}$ & $2,50^{3}$ & $0,05^{\mathbf{a}}$ & $-0,70^{\mathrm{a}}$ \\
\hline DF2 & $1,63^{a}$ & $1,69^{a}$ & $1,75^{\mathrm{a}}$ & $1,40^{\mathrm{a}}$ & $1,73^{\mathrm{a}}$ & $2,03^{a}$ & $2,56^{\mathrm{a}}$ & $1,93^{a}$ & $1,87^{\mathrm{a}}$ & $0,00^{a}$ & $0,93^{a}$ & $0,41^{\mathrm{a}}$ \\
\hline DF3 & $0,65^{a}$ & $1,28^{\mathrm{a}}$ & $2,89^{a}$ & $0,42^{a}$ & $0,24^{2}$ & $0,04^{a}$ & $0,51^{\mathrm{a}}$ & $0,61^{2}$ & $0,47^{a}$ & $0,00^{\mathrm{a}}$ & $1,14^{2}$ & $-0,25^{a}$ \\
\hline
\end{tabular}

Valores com letras diferentes, na mesma linha, diferem significativamente entre si pelo Teste de Tukey-Kramer $(\mathrm{P}>0,05)$.

Tabela 4 - Efeito das combinações entre os diferentes substratos (COL ou FB) e os diferentes tamanhos foliculares iniciais $($ TAM $1=<60 \mu \mathrm{m}$, TAM2 $=60$ a $80 \mu \mathrm{m}$, TAM3 $=>80 \mu \mathrm{m})$ sobre o aumento de diâmetro ( $\mu \mathrm{m})$ de folículos pré-antrais de fetos bovinos, em diferentes intervalos de tempo (DF1 $=0 \mathrm{~h}$ a $72 \mathrm{~h}$ DF2 $=72 \mathrm{~h}$ a $144 \mathrm{~h}, \mathrm{DF} 3=144 \mathrm{~h}$ a $216 \mathrm{~h})$. Jaboticabal, 2005

\begin{tabular}{ccccccc}
\hline \multirow{2}{*}{$\begin{array}{c}\text { Períodos de } \\
\text { Tempo }\end{array}$} & \multicolumn{5}{c}{ Combinações entre Substratos e Tamanhos Iniciais 1, 2 e 3 } \\
\cline { 2 - 7 } & $<\mathbf{6 0} \boldsymbol{\mu m}$ & $\mathbf{6 0} \mathbf{a} \mathbf{8 0} \boldsymbol{\mu m}$ & $>\mathbf{8 0} \boldsymbol{\mu m}$ & $<\mathbf{6 0} \boldsymbol{\mu m}$ & $\mathbf{6 0} \mathbf{a} \mathbf{8 0} \boldsymbol{\mu m}$ & $>\mathbf{8 0} \boldsymbol{\mu m}$ \\
\cline { 2 - 7 } & $5,13^{\mathrm{a}}$ & $1,67^{\mathrm{a}}$ & $1,97^{\mathrm{a}}$ & $0,70^{\mathrm{a}}$ & $1,40^{\mathrm{a}}$ & $0,79^{\mathrm{a}}$ \\
DF1 & $2,52^{\mathrm{a}}$ & $2,7^{\mathrm{a}}$ & $2,87^{\mathrm{a}}$ & $-0,70^{\mathrm{a}}$ & $-0,40^{\mathrm{a}}$ & $-0,27^{\mathrm{a}}$ \\
DF2 & $1,02^{\mathrm{a}}$ & $1,64^{\mathrm{a}}$ & $1,83^{\mathrm{a}}$ & $-0,23^{\mathrm{a}}$ & $0,00^{\mathrm{a}}$ & $-0,25^{\mathrm{a}}$ \\
\hline
\end{tabular}

Valores com letras diferentes, na mesma linha, diferem significativamente entre si pelo Teste de Tukey-Kramer $(\mathrm{P}>0,05)$. 
independentemente do tratamento aplicado ( $p>0,05)$.

\section{Discussão}

Este estudo confirmou o potencial de recuperação de grandes quantidades de folículos pré-antrais isolados de ovários de fetos bovinos pelo Tissue Chopper, como já demonstrado anteriormente ${ }^{11,22}$ ao contrário do que aconteceu em estudos que utilizaram digestão do tecido ovariano com enzimas como a colagenase ${ }^{22,23}$. A escolha da idade fetal como sendo o último trimestre de gestação corroboram com os resultados de Carambula et al..$^{24}$, sobre a recuperação de grande quantidade de folículos primários fetais. Além disso, a presença da membrana basal intacta ao redor do folículo aumenta aproveitamento de uma variedade de fatores e hormônios presentes no meio de cultivo. ${ }^{25}$ A preservação da morfologia folicular em diferentes estádios do desenvolvimento possibilita a adesão entre os componentes celulares e possibilita a aplicação de sistemas de cultivo in vitro.

Pelas observações microscópicas ao longo do cultivo e seguindo os critérios de avaliação dos estudos de Figueiredo et al. ${ }^{22}$, observamos que os folículos com morfologia preservada pelo tratamento apresentavam manutenção da sua estrutura tridimensional e preservação da viabilidade do oócito. Isto se confirmou pela permanência da membrana basal intacta, a qual mantinha compactadas as camadas de células granulosas ao redor do oócito, mesmo que não houvesse aumento de diâmetro folicular em alguns tratamentos. Folículos considerados morfologicamente degenerados não apresentaram danos na membrana basal, no entanto, o oócito estava condensado e contraído, o que alterava sua coloração, além disso, suas células granulosas apresentavam núcleos densos e escuros.

Muitos estudos demonstraram que folículos primordiais e pequenos folículos primários não apresentam crescimento in vitro satisfatório por mais de sete dias de cultivo $^{2,22,23,25,26}$, até mesmo quando se utiliza matrix extracelular como o colágeno. De forma similar aos resultados de Itoh e Hoshi ${ }^{27}$ não observamos formação de antrum ao final do período de cultivo em gel de colágeno, demonstrando a necessidade dos folículos pré-antrais bovinos de serem mantidos por um período muito longo em cultivo, o que ainda parece ser difícil de ser alcançado.

Nossos estudos demonstraram também que, folículos de diferentes tamanhos iniciais em todos os tratamentos, tiveram alterações no seu diâmetro ao longo de $216 \mathrm{~h}$ de cultivo in vitro, porém, nenhum dos tratamentos proporcionou crescimento folicular satisfatório para se iniciar a formação de antrum. Também ficou patente que as taxas de crescimento folicular foram semelhantes entre os tratamentos ao longo do período de cultivo (DF1, DF2, DF3) e, embora não significativos, nossos resultados confirmam outros estudos por demonstrar que a taxa de crescimento foi mais alta no início do cultivo tendo uma gradual redução com o passar do tempo. ${ }^{28,29}$ Além disso, o melhor sistema de cultivo dentre os nossos tratamentos resultou em taxa de crescimento inferior ao estudo de Saha et al. ${ }^{29}$, provavelmente devido a não utilização de fatores de crescimento, como por exemplo, o EGF.

Em concordância aos resultados desta pesquisa, estudos têm demonstrado a superioridade da suplementação com SFB sobre a manutenção do crescimento folicular, tanto em camundongos ${ }^{30}$, como em bovinos ${ }^{31}$. Por outro lado, existem dados enfatizando a eficiência de fontes energéticas, como piruvato e glutamina, sobre a sobrevivência folicular, pelo aumento da percentagem de folículos morfologicamente viáveis. ${ }^{32}$

Neste experimento, obteve-se um baixo crescimento folicular em comparação a outros estudos ${ }^{26,29,33}$ e somente os tratamentos com uso de colágeno como substrato tiveram aumento considerável do diâmetro folicular, ainda assim, apenas aquele suplementado com SFB apresentou taxa de crescimento significativamente maior $(20,71 \%) \quad(\mathrm{P}<0,05) . \quad$ Quando da suplementação com KNO, também houve 
aumento de diâmetro $(10,01 \%)$, porém não significativo considerando $p<0,05$. Embora não tenha havido crescimento satisfatório dos folículos em cultivo, concordamos com outro estudo ${ }^{29}$ sobre a maior eficiência do colágeno na preservação da estrutura tridimensional dos folículos, bem como sobre a melhor ação do SFB para a preservação da morfologia folicular ao longo do cultivo. Ainda utilizando colágeno, mesmo o grupo controle, sem qualquer suplementação protéica, foi mais efetivo sobre a preservação da viabilidade folicular quando comparado com os tratamentos conduzidos com monocamada de fibroblastos fetais.

O cultivo com fibroblastos, embora inativados com Mitomicina $C$, exerceu efeitos negativos sobre a viabilidade folicular à medida que acidificavam o meio de cultivo e induziam a degeneração folicular. Tais resultados diferem daqueles realizados em sistemas de co-cultivo, porém sem a adição de soro. ${ }^{27}$ Esse fator, provavelmente, diminuiu os efeitos do metabolismo das células somáticas sobre os folículos em cultivo e inibiu os possíveis efeitos positivos da liberação de fatores de crescimento, bem como do provimento de matrix extracelular, oriundos das células somáticas. Tais estudos mostraram que o co-cultivo de pequenos folículos pré-antrais por 30 dias com células do mesênquima ovariano bovino, ou fibroblastos fetais bovinos, ou ainda com células granulosas, poderiam resultar em formação de antrum. ${ }^{27}$ Neste sentido, faz-se necessário estabelecer outros sistemas de cocultivo com células somáticas a fim de avaliar quais seriam seus reais efeitos sobre os folículos pré-antrais in vitro. Os resultados dos nossos estudos mostraram ainda que diferentes fontes protéicas podem ser adicionadas ao meio de cultivo de escolha para potencializar odesenvolvimento folicular. A pesquisa de Ali e Sirard ${ }^{12}$ demonstrou que a substituição de SFB por
BSA aumentou a produção de blastocistos, e o uso de Polivinilpirrolidona proporcionou resultados ainda melhores na obtenção de embriões. Contrariamente, nossos resultados demonstraram que o BSA foi menos efetivo sobre o aumento de diâmetro folicular em relação ao SFB e que, o Knockout ${ }^{\mathrm{TM}}$ SR, pode ser um substituto do soro, embora seus efeitos tenham sido significativamente inferiores $(\mathrm{p}<0,05)$.

Este é um dos primeiros estudos que define o aumento no diâmetro de folículos pré-antrais isolados de ovários de fetos bovinos da raça Nelore cultivados in vitro. Sob estas condições de cultivo não houve diferenças sobre a taxa de crescimento folicular ao longo de nove dias de cultivo, entre a utilização de folículos primários iniciais, primários avançados ou secundários, submetidos a qualquer dos tratamentos $\mathrm{e}$ avaliados em diferentes períodos de cultivo $(\mathrm{p}<0,05)$.

Assim, concluiu-se que a utilização de uma camada de gel de colágeno foi mais eficiente para a manutenção da viabilidade folicular, bem como para o aumento do diâmetro folicular, quando comparado ao uso de monocamada de fibroblastos fetais inativados. O cultivo in vitro de folículos préantrais isolados de ovários de fetos bovinos é mais efetivo sobre o aumento do diâmetro folicular quando se utiliza soro fetal bovino comparado a outras fontes de macromoléculas como BSA ou KnockoutSR. Estes resultados representam mais um passo encorajador para o estabelecimento de um sistema de cultivo in vitro de folículos pré-antrais bovinos.

\section{Agradecimentos}

Agradecimentos à FAPESP, pelo suporte financeiro recebido por meio de bolsa de doutorado (01/09988-1) e auxílio à pesquisa (02/10168-1).

\section{Effects of different systems of in vitro culture on the isolated preantral follicles from fetal bovine ovaries}


Abstract

Key words:

Preantral.

The objective of this study is to use different in vitro culture systems Follicle. of preantral follicles from Nelore breed bovine fetuses in the last In vitro culture. gestation quarter. The evaluation of treatments considered the time of growth of isolated follicles. Preantral follicles were mechanically isolated and submitted to the individual culture, for 9 days, in media no supplemented or supplemented with fetal calf serum (FCS), bovine serum albumin (BSA) or synthetic defined supplement substitute of serum KnockoutSR (KNO). We have also evaluated the effects of collagen gel or fetal calf fibroblast monolayer as substratum for in vitro cultures. The increase on the follicular diameter was followed in the first day (0 h), at the $72 \mathrm{~h}, 144 \mathrm{~h}$ and $216 \mathrm{~h}$. Considering cultures of isolated follicles, the results have shown that the association between media supplemented with FCS and collagen gel was significantly more efficient on the increase of the follicular diameter than other treatments. It is not still established a system of appropriate cultivation that sustains the differentiation and multiplication of the granular cells and that maintains the contact of the same ones with the oocyte to provide molecules and factors that supply the metabolic demand. We also understand that our results also represent another promising step on the search for the ultimate system of in vitro culture of preantral follicles from bovines.

\section{Referências}

1 CAMPBELL, B.; SCARAMUZZI, R.; WEBB, R. Control of antral follicle development and selection in sheep and cattle. Journal of Reproduction and Fertility, v. 49, p. 335-350, 1995.

2 WANDJI, S. A. et al. Initiation in vitro of growth of bovine primordial follicles. Biology of Reproduction, v. 55, p. 942-948, 1996.

3 RICHARDS, J. Perspective: the ovarian follicle-A perspective in 2001. Endocrinology, v. 142, p. 21842193, 2001.

4 CAMPBELL, B. K. et al. Evidence of a role for folliclestimulating hormone in controlling the rate of preantral follicle development in sheep. Endocrinology, v. 145, n. 4, p. 1870-1879, 2004.

5 EPPIG, J. J.; SCHROEDER, A. C. Capacity of mouse oocytes from preantral follicles to undergo embryogenesis and development to live young after growth, maturation and fertilization in vitro. Biology of Reproduction, v. 41, p. 268-276, 1989.

6 TELFER, E. E. The development of methods for isolation and culture of preantral follicles from bovine and porcine ovaries. Theriogenology, v. 45, p. 101-110, 1996.

7 HULSHOF, S. C. J. et al. Effects of fetal bovine serum, FSH and 17B-estradiol on the culture of bovine preantral follicles. Theriogenology, v. 44, p. 217-226, 1995.

8 OKTAY, K. et al. Isolation and characterization of primordial follicles from fresh and cryopreserved human ovarian tissue. Fertility and Sterility, v. 67, p. 481-486, 1997.
9 SILVA, J. R. V. et al. Influences of FSH and EGF on primordial follicles during in vitro culture of caprine ovarian cortical tissue. Theriogenology, v. 61, p. 16911704, 2004.

10 HOVATTA, O.; SILYE, R.; ABIR, R. Extracellular matrix improves survival of both stored and fresh human primordial and primary ovarian follicles in long-term culture. Human Reproduction, v. 12, p. 1032-1036, 1997.

11 BASSO, A. C.; ESPER, C. R. Isolamento e caracterização ultraestrutural de folículos pré-antrais de vacas da raça Nelore (Bos taurus indicus). Brazilian Journal of Veterinary Research and Animal Science, São Paulo, v. 39, n. 6, p. 311-319, 2002.

12 ALI, A.; SIRARD, M. A. Effect of the absence or presence of various protein supplements on further development of bovine oocytes during in vitro maturation. Biology of Reproduction, v. 66, p. 901905, 2002.

13 ROSE, T. A.; BAVISTER, B. D. Effect of oocyte maturation medium in vitro development of in vitro fertilized bovine embryos. Molecular Reproduction and Development, v. 31, p. 72-77, 1992.

14 TORRANCE, C.; TELFER, E. E.; GOSDEN, R. G. Quantitative study of the development of isolated mouse pre-antral follicles in collagen gel culture. Journal of Reproduction and Fertility, v. 87, p. 367-374, 1989.

15 HIRAO, Y. N. In vitro growth and maturation of pig oocytes. Journal of Reproduction and Fertility, v. 100, p. 333-339, 1994. 
$16 \mathrm{ABIR}$, R. et al. Mechanical isolation and in vitro growth of preantral and small antral human follicles. Fertility and Sterility, v. 68, p. 682-688, 1997.

17 ADRIAENS, I.; CORTVRINDT, R.; SMITZ, J. Differential FSH exposure in preantral follicle culture has marked effects on folliculogenesis and oocyte developmental competence. Human Reproduction, v. 19, n. 2, p. 398-408, 2004.

18 GOSDEN, R.; NAGANO, M. Preservation of fertility in nature and ART. Reproduction, v. 123, p. 3-11, 2002.

19 SCHWERIN, M. Molecular genome analysis in livestock at the beginning of the new millennium. Reproduction in Domestic Animals, v. 36, p. 133138, 2001.

20 McNATTY, K. et al. Growth and paracrine factors regulating follicular formation and cellular function. Journal of Molecular Endocrinology, v. 163, p. 11-20, 2000.

$21 \mathrm{NICHOLS}, \mathrm{C}$. W. The embryology of the calf: fetal growth weights, relative age and certain body measurements. American Journal of Veterinary Research, v. 5, p. 135-141, 1944.

22 FIGUEIREDO, J. R. et al. Development of a combined new mechanical and enzymatic method for the isolation of intact preantral follicles from fetal, calf and adult bovine ovaries. Theriogenology, v. 40, p. 789-799, 1993.

23 WANDJI, J. J.; EPPIG, J. J.; FORTUNE, J. E. FSH and growth factors affect the growth and endocrine function in vitro of granulosa cells of bovine preantral follicles. Theriogenology, v. 45, p. 817-832, 1996.

24 CARAMBULA, S. F. et al. Effect of fetal age and method of recovery on isolation of preantral follicles from bovine ovaries. Theriogenology, v. 52, p. 563571, 1999.

25 FIGUEIREDO, J. R. et al. Extracellular matrix proteins and basement membrane: their identification in bovine ovaries and significance for the attachment of cultured preantral follicles. Theriogenology, v. 43, p. 845-858, 1995.

26 FIGUEIREDO, J. R. et al. The physiological status of the ovarian donor affects in vitro development of isolated bovine preantral follicles. Theriogenology, v. 42, p. 1303-1310, 1994.

$27 \mathrm{ITOH}, \mathrm{T}$.; HOSHI, H. Efficient isolation and longterm viability of bovine small preantral follicles in vitro. In Vitro Cell Development Biology, v. 36, p. 235-240, 2000.

28 KATSKA, L.; RYNSKA, B. The isolation and in vitro culture of bovine preantral and early antral follicles of different size classes. Theriogenology, v. 50, p. 213222, 1998.

$29 \mathrm{SAHA}, \mathrm{S}$. et al. In vitro culture of bovine preantral follicles. Animal Reproduction Science, v. 63, p. 2739, 2000.

30 NAYUDU, P. L.; OSBORN, S. M. Factors influencing the rate of preantral and antral growth of mouse ovarian follicles in vitro. Theriogenology, v. 95. p. 349-362, 1992.

31 FIGUEIREDO, J. R. et al. Preservation of oocyte and granulosa cell morphology in bovine preantral follicles cultured in vitro. Theriogenology, v. 41, p. 1333-1346, 1994.

32 JEWGENOW, K. Role of media, protein and supplements on maintenance of morphology and DNAsynthesis of small preantral domestic cat follicles during short-term culture. Theriogenology, v. 49, p. 1567-1577, 1998.

33 GUTIERREZ, C. G. et al. Growth and antrum formation of bovine preantral follicles in long-term culture in vitro. Biology of Reproduction, v. 62, p. 1322-1328, 2000.

34 BOLAND, N. I.; HUMPHERSON, P. G.; GOSDEN, R. G. Pattern of lactate production and steroidogenesis during growth and maturation of mouse ovarian follicles in vitro. Biology of Reproduction, v. 48, p. 798-806, 1993.

35 PICTON, H. et al. Initiation of human primordial follicle growth in vitro in ultra thin slices of ovarian cortex. Human Reproduction, v. 14, p. 2-11, 1999.

36 WEBB, R. et al. Molecular mechanisms regulating follicular recruitment and selection. Journal of Reproduction and Fertility, v. 53, p. 33-48, 1999. 


\section{INSTRUÇÕES AOS AUTORES}

\section{Normas editoriais}

O periódico Brazilian Journal of Veterinary Research and Animal Science é publicado bimestralmente pela Fundação de Medicina Veterinária (FUMVET) e destina-se a publicar trabalhos científicos Os trabalhos encaminhados para publicação são submetidos à aprovação do Comissão Editorial, com assessoria de especialistas da área (peer review). A lista de colaboradores (relatores) é publicada no último fascículo/ano de cada volume. Os trabalhos cujos textos necessitarem de revisões ou correções que não puderem ser feitas pelos editores seráo devolvidos aos autores. Os aceitos para publicação tornam-se propriedade dessa revista. Os
autores são responsáveis pelos conceitos e informações neles contidos. No momento da submissão do trabalho à revista é obrigatório apresentar a aprovação do protocolo experimental por Comitê de Ética. Qualquer que seja o tipo do trabalho, deverá ser inédito e destinarse exclusivamente a esse periódico, sendo obrigatório anexar declaração assinada por todos os autores expressando concordância no pagamento de tarifa como condicionante à sua publicação.

Os trabalhos para publicação deverão ser encaminhados a:

Brazilian Journal of Veterinary Research and Animal Science

Setor de Publicação

Av. Prof. Dr. Orlando de Marques

Paiva, 87

Cidade Universitária "Armando de

Salles Oliveira"

CEP 05508-270 - São Paulo - SP -

Brasil

Telefone: 0055113091 1472/ 3091

7636

Fax: 00551130917636

e-mail: bjvras@fumvet.com.br

\section{Artigo completo}

1 - Limitar-se ao máximo de dez páginas digitadas, dentro da estrutura do item cinco, não sendo contadas as páginas onde constem tabelas e ilustrações. 2 . Ser escrito em língua portuguesa ou em língua inglesa. 3 - Usar somente nomenclaturas oficiais e abreviaturas consagradas, não empregando abreviaturas no título do artigo. 4 - Ser estruturado dentro dos seguintes itens: a) Introdução; b) Materiais e Métodos; c) Resultados; d) Discussão; e) Conclusões; f) Referências; g) Resumo/Palavras-chave Abstract/Key-words. 5 - Apresentar, obrigatoriamente, dois resumos, nos idiomas inglês e português, não devendo ultrapassar 250 (duzentas e cinqüenta) palavras, seguidos das palavras-chave, limitadas a cinco, que correspondem a palavras ou expressões que identificam o conteúdo do artigo.

\section{Nota prévia}

1 - Limitar-se ao máximo de três páginas digitadas. 2 - Ser escrita em língua portuguesa ou em língua inglesa. 3 - Usar somente nomenclaturas oficiais e abreviaturas consagradas, não artigo. 4 - Não devem ser subdivididos em seções separadas (Introdução, Materiais e Métodos etc.), mas devem resumos, com palavras-chave, conforme descrito na apresentação de Artigo completo, além de referências.

\section{Artigos de revisão}

Só poderão ser publicados por especialistas de renome a convite da subdivididos em seções separadas (Introdução, Materiais e Métodos etc.), mas devem apresentar, obrigatoriamente, dois resumos, com palavras-chave, Artigo completo, além de referências.

\section{Apresentação dos trabalhos}

1 - Digitação: original em $C D$, devidamente identificado com o título do artigo e nome do(s) autor(es) e três cópias impressas, inclusive suas tabela e referências; deve ser digitado, obrigatoriamente, em formato A4 $(21,0 \times$ $29,7 \mathrm{~cm}$ ), espaço duplo, em uma só face de papel, margens de $2,5 \mathrm{~cm}$, fonte Times New Roman tamanho 10 e numeração consecutiva das páginas. Ilustrações e legendas devem ser relacionadas em folhas separadas. O texto dos artigos deve ser apresentado utilizando-se o editor de texto Microsoft Word. 2 - Página de rosto: elemento obrigatório, onde deve conter o título do artigo, nome(s) do(s) autor(es) e instituição de origem. Observar que unicamente nesta página conste a identificação dos autores, para o devido sigilo e imparcialidade. No rodapé da página deve-se mencionar o endereço completo (inclusive e-mail) do autor para correspondência. Se o artigo for subvencionado, mencionar a instituição que o patrocinou, assim como os agradecimentos; 3 - Tabelas: devem ser numeradas em algarismos arábicos encabeçadas pelo título, seguido de local e data. Na montagem das tabelas seguir: IBGE. Normas de apresentação tabular. 3. ed. Rio de Janeiro: IBGE, 1993. 61 p. O limite de tabelas por trabalho é de cinco. Em casos excepcionais, conhecida a opinião da Comissão Editorial, este número poderá ser ultrapassado. No texto devem ser indicadas pela palavra Tabela (por extenso). 4 - Ilustrações (fotografias, gráficos, quadros, desenhos ou esquemas): devem ser numeradas consecutivamente com algarismos arábicos e citadas como figuras no texto. As fotografias devem ser identificadas somente com o título do artigo, além de conter no verso a indicação de seu correto posicionamento. Fotos fornecidas em papel fotográfico devem ter ótima resolução, em CD com a extensão. TIF e resolução mínima de $300 \mathrm{dpi}$ s. As legendas de ilustrações coloridas devem estar referenciadas somente por setas, símbolos e pontos quando publicadas em preto e branco. Gráficos, desenhos ou esquemas devem ser fornecidos no Com folha à parte f. Tese (Livre Docência) - Faculdade de Com o título do Medicina Veterinária e Zootecnia artigo, além das respectivas legendas. (sem itálico). em três vias. Os gráficos devem trazer Exemplo de evento

sempre os valores numéricos que lhes origem. Desenhos e esquemas artística. Aceitar-se-á um número máximo de nove ilustrações por artigo, sugerindo-se a seguinte distribuição: três otografias, três gráficos e três desenhos/ esquemas. Acima deste limite, as despesas com reprodução correrão por conta do autor. Ilustrações coloridas, independentemente do número, serão cobradas. No texto devem ser indicadas pela palavra Figura (por extenso). Indicar junto ao título da ilustração o local e data. 5 - Referências: devem ser
numeradas, ao final do artigo, de forma consecutiva de acordo com a ordem em que forem sendo citadas no texto. Os títulos de periódicos devem ser
mencionados de maneira uniforme, de preferência todos por extenso. As referências seguem a normalização da Associação Brasileira de Normas Técnicas (ABNT) NBR 6023, que deve ser documentos aqui não exemplificados.

Exemplos de Apresentação dos Autores nas Referências:

BONAGURA, J. D. (um autor) SANTOS, J. A.; MELLO, M. R. (dois autores)

BENNETT, B. T.; ABEE, C. R.;

HENRICKSON, R. (três autores)

VILELA, D.; MARTINS, C. E.; BRESSAN M.; CARVÁLHO, L. A. [...] (quatro autores ou mais) ou VILELA, D. et al.

\section{Exemplo de periódico}

1 KOTZEKIDOV, P.; BLOUKAS, J. G.

Effect of protective cultures and

packaging film permeatibility on

shelflife of sliced vacuum-pocked

cooked ham. Meat Science, v. 42, n. 3, p. 333-345, 1996.

Exemplo de livro

2 HALLIWELL, R. E. W.; GORMAN, N. $T$. Veterinary clinical immunology. London: W. B. Saunders, 1989. 548 p.

Exemplo de autor diferente para o livro e capítulo

3 FENNER, W. R. Avaliação neurológica dos pacientes. In: ETTINGER, S. J. Tratado de medicina interna veterinária. 3. ed. São Paulo: Manole, 1992. p. 577-606.

\section{Exemplo}

4 THORTON, $\mathrm{H}$. Deleterius changes in meat. In: THORTON, H. Aspects of meat inspection. London: Thindall \& Cassel, 1973. p. 63-72.

\section{Exemplo de tese}

5 BIRGEL, E. H. Estudo do quadro eritrocitário de caprinos (Capra hircus, L) normais criados no Estado de São Universidade de São Paulo, São Paulo 1973.
6 OLIVEIRA, C. A. Hormonoterapia em cadelas e gatas. In: CONGRESSO

BRASILEIRO DE REPRODUÇÃO

ANIMAL, 9., 1991, Belo Horizonte.

Anais... Belo Horizonte: Colégio Brasileiro de Reprodução Animal, 1991. p. 100-111.

Exemplo de livro eletrônico 7 POORE, M. H. Alternative feeds for beef cattle. North Carolina: North Carolina Corporative Extension Service, 1994. Disponível em: <http:// www.ces.ncsu.edu/drought/dro28.html >. Acesso em: 23 abr. 2007.

Exemplos de artigos de periódicos eletrônicos

3 MENDONÇA JR., C. X.; MARTINS, A. .; MORI, A. V.; SILVA, A. B.; MORI, C.

Efeito da adição de óleo de peixe à dieta sobre o desempenho e níveis de lípides plasmáticos e de colesterol no ovo de galinhas poedeiras. Brazilian

ournal of Veterinary Research and

Animal Science, v. 37, n. 1, 2000.

Disponível em: < http://www.scielo.br/ cgi_bin/wxis.exe/iach/scielo $>$. Acesso em: 31 jan. 2001

6 - Citações: utilizar o Sistema Numérico. As citações devem ser feitas por numeração única e consecutiva em sobrescrito, utilizando-se algarismos arábicos, remetendo à lista de referências na mesma ordem em que aparecem no texto. Quando indispensável para a compreensão do texto, combinar o(s) sobrenome(s) do(s) autor(es) com a indicação do número. Neste caso, a citação será pelo sobrenome de cada autor ou pelo nome da entidade responsável que aparece na respectiva referência. Quando se tratar de três autores, todos devem ser citados. No caso de mais de três autores, a citação deve ser acompanhada pelo sobrenome do primeiro autor seguido da expressão et al. (sem itálico). Se a citação estiver inserida no texto utilizar letras maiúsculas e minúsculas; se estiver entre parênteses utilizar somente letras maiúsculas.

Exemplos:

Um autor

Segundo Yanaguita ${ }^{9}$ ou (YANAGUITA ${ }^{9}$ )

\section{Dois autores}

Soares e Alves ${ }^{13}$ ou (SOARES; ALVES ${ }^{13}$ )

Três autores

Bennett, Abee e Henrickson ${ }^{12}$ ou (BENNETT; ABEE; HENRICKSON ${ }^{12}$ )

Quatro ou mais autores

Vilela, Martins, Bressan e Carvalho ${ }^{26}$ ou Vilela et al. ${ }^{26}$

(VILELA; MARTINS; BRESSAN

CARVALHO ${ }^{26}$ ) OU (VILELA et al. ${ }^{26}$ )

Tarifa de publicacão: A tarifa de publicação de $R \$ 40,00$, por página impressa, será cobrada do autor indicado para correspondência, por ocasião da prova final do artigo. Se houver necessidade de impressão em cores, as despesas correrão por conta dos autores.

Obs.:Esclarecemos que nos trabalhos envolvendo experimentação animal, a critério dos senhores relatores, poderão ser solicitados certificados de aprovação dos Comitês de Bioética. Os artigos submetidos à publicação, uma vez aprovados, estão condicionados ao pagamento de taxa em moeda nacional (R\$) a ser estabelecida na época de sua publicação, cujo cálculo levará em conta o total de páginas diagramadas que o artigo ocupar na revista. 